Article

\title{
Physico-Chemical Properties and Phase Behaviour of Pyrrolidinium-Based Ionic Liquids
}

\section{Urszula Domańska}

Department of Physical Chemistry, Faculty of Chemistry, Warsaw University of Technology, Noakowskiego 3, 00-664 Warsaw, Poland; E-Mail: Ula@ch.pw.edu.pl; Tel.: +48-22-6213115; Fax: $+48-22-6282741$

Received: 23 February 2010; in revised form: 25 March 2010 / Accepted: 20 April 2010 / Published: 21 April 2010

Abstract: A review of the relevant literature on 1-alkyl-1-methylpyrrolidinium-based ionic liquids has been presented. The phase diagrams for the binary systems of \{1-ethyl-1-methylpyrrolidinium trifluoromethanesulfonate (triflate) [EMPYR] $\left.\mathrm{CF}_{3} \mathrm{SO}_{3}\right]+$ water, or +1 -butanol $\}$ and for the binary systems of \{1-propyl-1-methylpyrrolidinium trifluoromethanesulfonate (triflate) $[\mathrm{PMPYR}]\left[\mathrm{CF}_{3} \mathrm{SO}_{3}\right]+$ water, or + an alcohol (1-butanol, 1-hexanol, 1-octanol, 1-decanol)\} have been determined at atmospheric pressure using a dynamic method. The influence of alcohol chain length was discussed for the [PMPYR $]\left[\mathrm{CF}_{3} \mathrm{SO}_{3}\right]$. A systematic decrease in the solubility was observed with an increase of the alkyl chain length of an alcohol. (Solid + liquid) phase equilibria with complete miscibility in the liquid phase region were observed for the systems involving water and alcohols. The solubility of the ionic liquid increases as the alkyl chain length on the pyrrolidinium cation increases. The correlation of the experimental data has been carried out using the Wilson, UNIQUAC and the NRTL equations. The phase diagrams reported here have been compared to the systems published earlier with the 1-alkyl-1-methylpyrrolidinium-based ionic liquids. The influence of the cation and anion on the phase behaviour has been discussed. The basic thermal properties of pure ILs, i.e., melting temperature and the enthalpy of fusion, the solid-solid phase transition temperature and enthalpy have been measured using a differential scanning microcalorimetry technique.

Keywords: 1-alkyl-1-methylpyrrolidinium-based ionic liquids; (solid + liquid) phase equilibria; water; alcohols; correlation; differential scanning microcalorimetry 


\section{Introduction}

Thanks to their interesting properties ionic liquids (ILs) are driving new research in many fields because of the interest in finding alternatives for conventional organic solvents. Their specific properties of a broad temperature range of liquid phase, extremely low vapour pressure, air and moisture stability, and specific electrochemical properties make ILs potentially useful in many technological processes [1-11]. The pyrrolidinium-based ILs were used in the preparation of a novel class of polymer electrolytes based on polymer-ionic liquid gels, which can be applied in electrochemical devices, especially in chemical capacitors [1-3]. They showed excellent performance as mechanically and electrochemically stable polymer matrixes for polymer electrolyte compositions with a wide electrochemical stability window (7.0V) [4]. The electrochemical reduction of palladium halide complexes, of nanocrystalline $\mathrm{ZnO}$ films and of tantalum and polycrystalline gold substrates using 1-butyl-1-methylpyrrolidinium bis(trifluoromethylsulfonyl)imide, [BMPYR][NTf $\left.{ }_{2}\right]$, was presented as well [5-7]. The conformational structure of the pyrrolidinium-based ionic liquid [BMPYR][NTf ${ }_{2}$ is well known [8] and is responsible for the interactions in the solutions. The pyrrolidinium-based IL was found to show a high ability to aggregate in aqueous solution, demonstrating its potential applicability as surfactant [9]. 1-Butyl-1-methylpyrrolidinium triflate was used in the catalytic processes with good economy, simplicity and as a recyclable medium [10]. The use of chromatographic and spectroscopic methods to establish the fundamental physico-chemical properties of over $200 \mathrm{ILs}$, including [BMPYR][NTf 2 , were described [11].

During the last ten years, measurements of the thermophysical and thermodynamic properties of ILs have increased remarkably, but they are not exhaustive enough for many new projects. Knowledge of the phase equilibria (vapour + liquid phase equilibrium, VLE, liquid + liquid phase equilibrium, LLE and solid + liquid phase equilibrium, SLE) is important if ILs are to be considered as solvents in technological processes [12-22]. The critical properties of ILs, including the pyrrolidinium-based ILs, and calculated by group contribution were presented by Valderrama and Rojas [12]. The first probe of the distillation of some ILs, including [BMPYR][ $\left.\mathrm{NTf}_{2}\right]$, even though they exert no measurable vapour pressure, was made in a Kugelrohr apparatus at $573 \mathrm{~K}$ and at 6-8 mbar pressure [13]. The VLE data for [BMPYR][NTf $\left.{ }_{2}\right]$ with alkanes and alkenes showed the possible use of this IL in the alkane/alkene separation process $[14,15]$. The mod. UNIFAC (Dortmund) parameters were developed from VLE, activity coefficients at infinite dilution and excess enthalpies and were used in the prediction of the separation processes [14,15]. The heat capacities and heats of solution of 1-propyl-1-methylpyrrolidine bis(trifluoromethylsulfonyl)imide were measured in water, methanol and acetonitrile [16]. The densities of pyrrolidinium-based ionic liquids over a wide range of temperatures were measured and calculated using the Ye and Shreeve group contribution method [14,15,17]. Essentially, all of the solvents available for chemical engineering processes to control reactions, perform separations and process materials are usually common liquids such as toluene, benzene, acetonitrile, ethanol and water. The ionic liquids have a chance to revolutionize the way new technology is planned. After years of measurements of phase equilibria and of activity coefficients at infinite dilution we can conclude that the pyrrolidinium-based ionic liquids are very promising [14,15,18-22]. In the process of desulfurization of oils using ionic liquids (extraction of dibenzothiophene from dodecane using ILs), the pyrrolidinium-based ILs have shown the same selectivities as popular imidazolium-based ionic 
liquids, but worse than pyridinium-based ILs [19]. Recently, [BMPYR][NTf 2 ] was described as a suitable solvent for extraction of aromatic hydrocarbons (benzene, toluene and ethylbenzene) from aliphatic hydrocarbons (heptane) [20]. The selectivity of a particular IL can be calculated for the different separation problems from measurements of the activity coefficient at infinite dilution [14,15,21,22]. The activity coefficient for various solutes (alkanes, alkenes, cycloalkanes, aromatics, alcohols, ketones, esters, ethers and water) were measured in the pyrrolidinium-based ILs: [BMPYR][NTf ${ }_{2}$ [14,15,21], [HMPYR][NTf $]$ [15], [OMPYR][NTf ${ }_{2}$ [15], and 1-butyl-1-methylpyrrolidinium triflate [BMPYR] $\left[\mathrm{CF}_{3} \mathrm{SO}_{3}\right][22]$. An entrainer should show a high selectivity at infinite dilution, a low viscosity, a high flash point, a low melting point and a boiling point higher that those of the separated components. Furthermore, it should be non-toxic, non-flammable, non-corrosive and recyclable. The pyrrolidinium-based ILs were found to be suitable as entrainers for the separation of aliphatic hydrocarbons from aromatic hydrocarbons, and of aromatic sulfur compounds from aliphatic hydrocarbons [20-22]. Repeated [BMPYR] $\left[\mathrm{CF}_{3} \mathrm{SO}_{3}\right]$ showed higher selectivity in the separation of aliphatic hydrocarbons from aromatic hydrocarbons than the popular imidazolium ionic liquid [BMIM] $\left[\mathrm{CF}_{3} \mathrm{SO}_{3}\right]$ [22]. On the other hand, the triflate anion showed much better selectivity than the bis(trifluoromethylsulfonyl)imide anion with the same cations in the different separation processes as for the examples mentioned above and alkane/thiophene [22].

Recent works have shown that some pyrrolidinium-based ILs have the potential to be good solvents for separating organic liquids using solvent extraction or extractive distillation processes with water $[23,24]$. In particular, the use of ILs with lower mutual solubilities with water as biphasic extraction media for the removal of organic compounds from water which is useful for industrial processes. The LLE of [PMPYR][NTf 2 ] and [BMPYR][ $\left.\mathrm{NTf}_{2}\right]$ with water were measured and predicted by the COSMO-RS $[23,24]$. The hydrophobic pyrrolidinium-based ILs have shown better solubility in water than piperidinium-based ILs and worse solubility in water than imidazolium-based and pyridinium-based ILs. Furthermore, the hydrophobicity of the alkyl-pyrrolidinium-based ILs increases when the alkyl chain length on the cation increases [24]. It is however the thermodynamic information, which reflects how the different IL interact with water, that is crucial in assessing its usefulness and allows one to predict the better and more efficient IL.

Recently, the mutual solubility of a pyrrolidinium-based IL, namely 1-butyl-1-methylpyrrolidinium triflate [BMPYR] $\left[\mathrm{CF}_{3} \mathrm{SO}_{3}\right]$, in hydrocarbons (hexane, heptane, cyclohexane, benzene, toluene) was measured in our laboratory [25]. It was shown using phase equilibria study of binary systems that aliphatic hydrocarbons are weakly soluble in [BMPYR] $\left[\mathrm{CF}_{3} \mathrm{SO}_{3}\right]$, whereas aromatic compounds are very soluble in this IL [25]. These are however, typical properties of many other ILs [26-29]. Phase equilibria results are also important in expanding our knowledge about the nature of ILs and in assisting in the systematic study of their thermodynamic properties. These results are also a good indication that the ILs involved will show good extraction properties. It was found that the investigated ILs could be very good entrainers for the separation of sulfur compounds from alkanes, as thiophene was completely soluble over a wide range of temperature [28]. Generally, the selectivity for the separation of aromatic hydrocarbons from the aliphatic hydrocarbons decreases with increasing length of the alkyl chain on the imidazolium, pyridinium, or pyrrolidinium cation, or on the anion of the IL. 
The phase diagram of the 1-ethyl-1-methylpyrrolidinium bis(trifluoremethylsulfonyl)imide, [EMPYR] $\left[\mathrm{NTf}_{2}\right]$ with benzene was presented as an eutectic system with the miscibility gap in the liquid phase at the solvent rich phase [29].

One of the aims of this work was to measure solubilities of two pyrrolidinium-based ILs: 1-ethyl-1-methylpyrrolidinium trifluoromethanesulfonate (triflate) [EMPYR] $\left[\mathrm{CF}_{3} \mathrm{SO}_{3}\right]$ in water, or in 1-butanol $\}$ and of 1-propyl-1-methylpyrrolidinium trifluoromethanesulfonate (triflate) [PMPYR] $\left[\mathrm{CF}_{3} \mathrm{SO}_{3}\right]$ in water, or in an alcohol (1-butanol, 1-hexanol, 1-octanol, 1-decanol)\} at atmospheric pressure using a dynamic method. The investigation also includes a discussion of the effect of the alkyl chain length of the alcohol and the alkyl chain length on the pyrrolidinium ring on solubility.

\section{Results and Discussion}

The phase diagrams of new binary \{ionic liquid + water, or + an alcohol $\}$ systems were determined. The structures of the ILs are presented in Table 1. A brief thermophysical characterization of the two ILs is presented in Table 2.

Table 1. Abbreviations, names and structures of investigated ionic liquids.

\begin{tabular}{cccc}
\hline Abbreviation & Name & Structure \\
\hline$[\mathrm{EMPYR}]\left[\mathrm{CF}_{3} \mathrm{SO}_{3}\right]$ & 1-ethyl-1- \\
& methylpyrrolidinium triflate & $\begin{array}{c}\text { 1-propyl-1- } \\
{[\mathrm{PMPYR}]\left[\mathrm{CF}_{3} \mathrm{SO}_{3}\right]}\end{array}$ \\
methylpyrrolidinium triflate
\end{tabular}

Table 2. Thermophysical constants of pure ILs (DSC data).

\begin{tabular}{|c|c|c|c|c|c|c|c|}
\hline Ionic liquid & $\begin{array}{c}M / \\
\mathrm{g} \cdot \mathrm{mol}^{-1}\end{array}$ & $\begin{array}{c}V_{\mathrm{m}}^{298.15} / \\
\mathrm{cm}^{3} \cdot \mathrm{mol}^{-1}\end{array}$ & $T_{\text {fus }} / \mathbf{K}$ & $\begin{array}{c}\Delta_{\text {fus }} \boldsymbol{H} / \\
\mathbf{k J} \cdot \mathbf{m o l}^{-1}\end{array}$ & $T_{\mathrm{tr}} / \mathrm{K}$ & $\begin{array}{c}\Delta_{\mathrm{tr}} \boldsymbol{H} / \\
\mathrm{kJ} \cdot \mathbf{m o l}^{-1}\end{array}$ & $\begin{array}{c}\Delta_{\text {fus }} C \mathbf{p}^{\mathrm{a} /} \\
\mathbf{J} \cdot \mathbf{m o l}^{-1} \cdot \mathbf{K}^{-1}\end{array}$ \\
\hline$[$ EMPYR $]\left[\mathrm{CF}_{3} \mathrm{SO}_{3}\right]$ & 263.26 & $239.6^{\mathrm{b}}$ & $\begin{array}{l}\text { 378.5(SLE) } \\
378.4(\mathrm{DSC})\end{array}$ & $9.99 \pm 0.05$ & 234.15 & $13.03 \pm 0.05$ & $0.06^{\mathrm{c}}$ \\
\hline$[\mathrm{PMPYR}]\left[\mathrm{CF}_{3} \mathrm{SO}_{3}\right]$ & 277.29 & $255.7^{\mathrm{b}}$ & 350.7 & $37.24 \pm 0.05$ & 205.15 & $1.92 \pm 0.05$ & 106.2 \\
\hline
\end{tabular}

The basic thermal properties of the ionic liquids i.e., temperature of fusion $\left(T_{\text {fus }}\right)$, enthalpy of fusion $\left(\Delta_{\text {fus }} H\right)$, (solid-solid) phase transition temperature $\left(T_{\text {tr }}\right)$ and the enthalpy change of (solid-solid) phase transition $\left(\Delta_{\mathrm{tr}} H\right)$ have been measured. The enthalpy of melting of [EMPYR][CF $\left.3 \mathrm{SO}_{3}\right]$ was found to be very small $\left(9.99 \pm 0.05 \mathrm{~kJ} \cdot \mathrm{mol}^{-1}\right)$ in comparison with $[\mathrm{PMPYR}]\left[\mathrm{CF}_{3} \mathrm{SO}_{3}\right]\left(37.24 \pm 0.05 \mathrm{~kJ} \cdot \mathrm{mol}^{-1}\right)$. This anomalous result can be explained by the second peak at DSC diagram for the (solid-solid) phase 
transition at a very low temperature $(234.15 \mathrm{~K}$ ) and with high enthalpy of phase transition (see Figure 1). The value of the enthalpy of the (solid-solid) phase transition $\left(13.03 \pm 0.05 \mathrm{~kJ} \cdot \mathrm{mol}^{-1}\right)$ is much higher than the enthalpy of melting. The value of heat capacity changes during the melting point ( $\Delta_{\text {fus }} \mathrm{Cp}$ ) was calculated from summarized values of $\Delta_{\text {fus }} H$ and $\Delta_{\mathrm{tr}} H$. The solubilities are the results of different interactions between the IL and water, or an alcohol. In this work the interaction may be due to the hydrogen bonding between pyrrolidinium ring of the cation and/or fluorine and oxygen atoms of the anion of the IL and of polar groups of the solvent. Unfortunately, both investigated ILs are solids at room temperature. It is known from the fundamental SLE discussion that the substance with the lower melting temperature and the lower enthalpy of melting is a better soluble in the same solvent.

Figure 1. The DSC diagrams for: (a) [EMPYR] $\left[\mathrm{CF}_{3} \mathrm{SO}_{3}\right]$, the whole range of temperatures; (b) $[E M P Y R]\left[\mathrm{CF}_{3} \mathrm{SO}_{3}\right]$, the lower temperature's peak; (c) [PMPYR] $\left[\mathrm{CF}_{3} \mathrm{SO}_{3}\right]$, the whole range of temperatures; [PMPYR] $\left[\mathrm{CF}_{3} \mathrm{SO}_{3}\right]$, the lower temperature's peak.

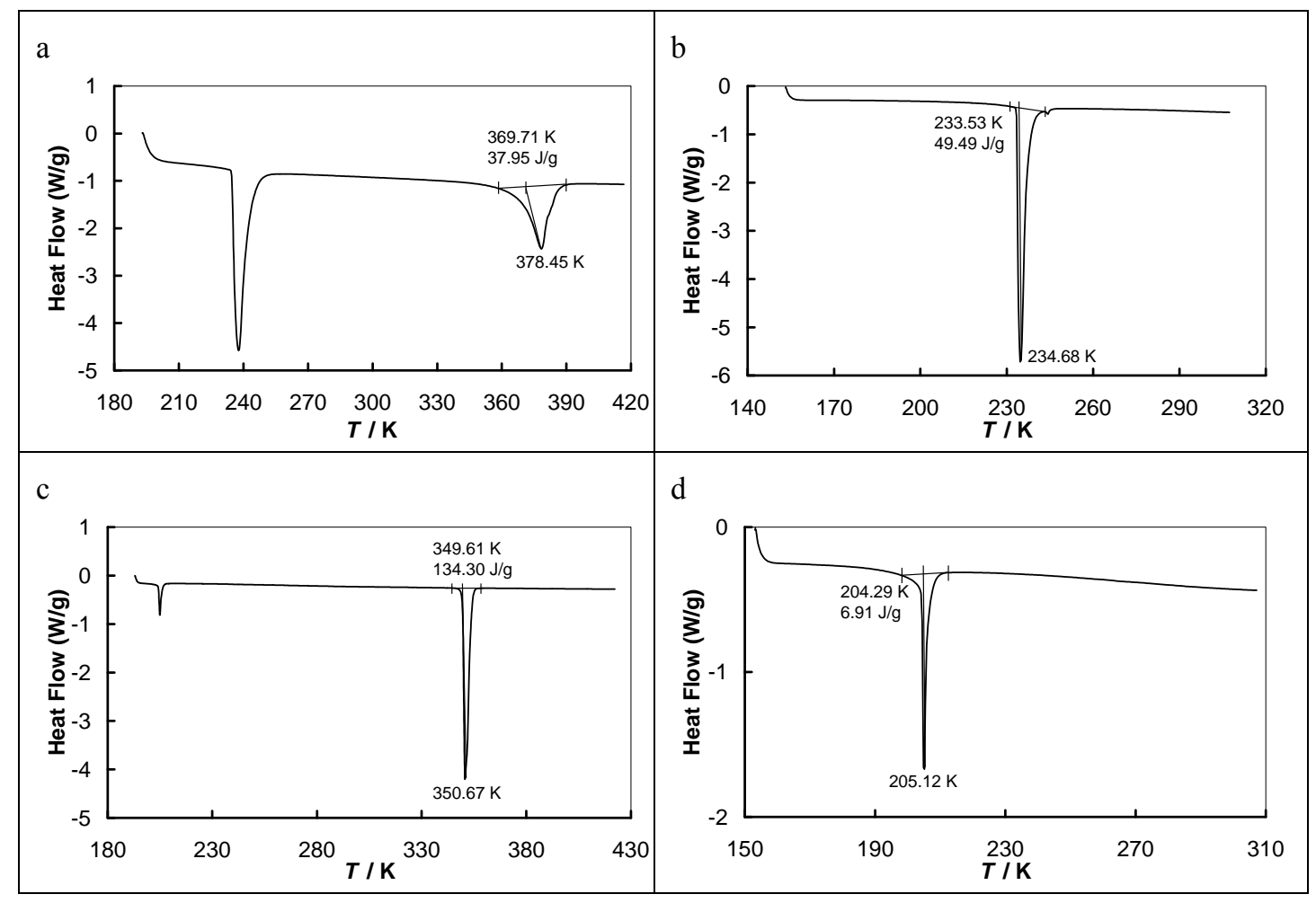

The experimental (solid + liquid) phase equilibrium data for the systems $\{\mathrm{IL}+$ water $\}$ are given in Figure 2. The experimental data, temperature, $T^{\mathrm{SLE}} v s$. mole fraction of the IL, $x_{1}$ are listed in Tables 3 and 4 for [EMPYR] $\left[\mathrm{CF}_{3} \mathrm{SO}_{3}\right]$ and [PMPYR] $\left[\mathrm{CF}_{3} \mathrm{SO}_{3}\right]$, respectively. The liquidus curves for the [EMPYR] $\left[\mathrm{CF}_{3} \mathrm{SO}_{3}\right]$ are almost the same as for $[\mathrm{PMPYR}]\left[\mathrm{CF}_{3} \mathrm{SO}_{3}\right]$. The $[\mathrm{EMPYR}]\left[\mathrm{CF}_{3} \mathrm{SO}_{3}\right]$ shows lower solubility than [PMPYR] $\left[\mathrm{CF}_{3} \mathrm{SO}_{3}\right]$ because of its higher melting temperature. The experimental eutectic points are: for $\left\{[\mathrm{EMPYR}]\left[\mathrm{CF}_{3} \mathrm{SO}_{3}\right]+\right.$ water $\}, x_{1, \mathrm{e}}=0.084, T_{\mathrm{e}} / \mathrm{K}=242.5$; and for $\left\{[\mathrm{PMPYR}]\left[\mathrm{CF}_{3} \mathrm{SO}_{3}\right]+\right.$ water $\}, x_{1, \mathrm{e}}=0.079, T_{\mathrm{e}} / \mathrm{K}=267.9$. The eutectic points are at the similar compositions, but at different temperatures. The eutectic points are shifted strongly to the solvent rich side. 
Figure 2. (Solid + liquid) phase equilibria of $\{\mathrm{IL}+$ water $\}$ : (•) $\left[\mathrm{EMPYR}^{\mathrm{L}}\right]\left[\mathrm{CF}_{3} \mathrm{SO}_{3}\right]$; $(\Delta)[P M P Y R]\left[\mathrm{CF}_{3} \mathrm{SO}_{3}\right]$. Solid lines designated by the Wilson equation. Dotted lines represent an ideal solubility.

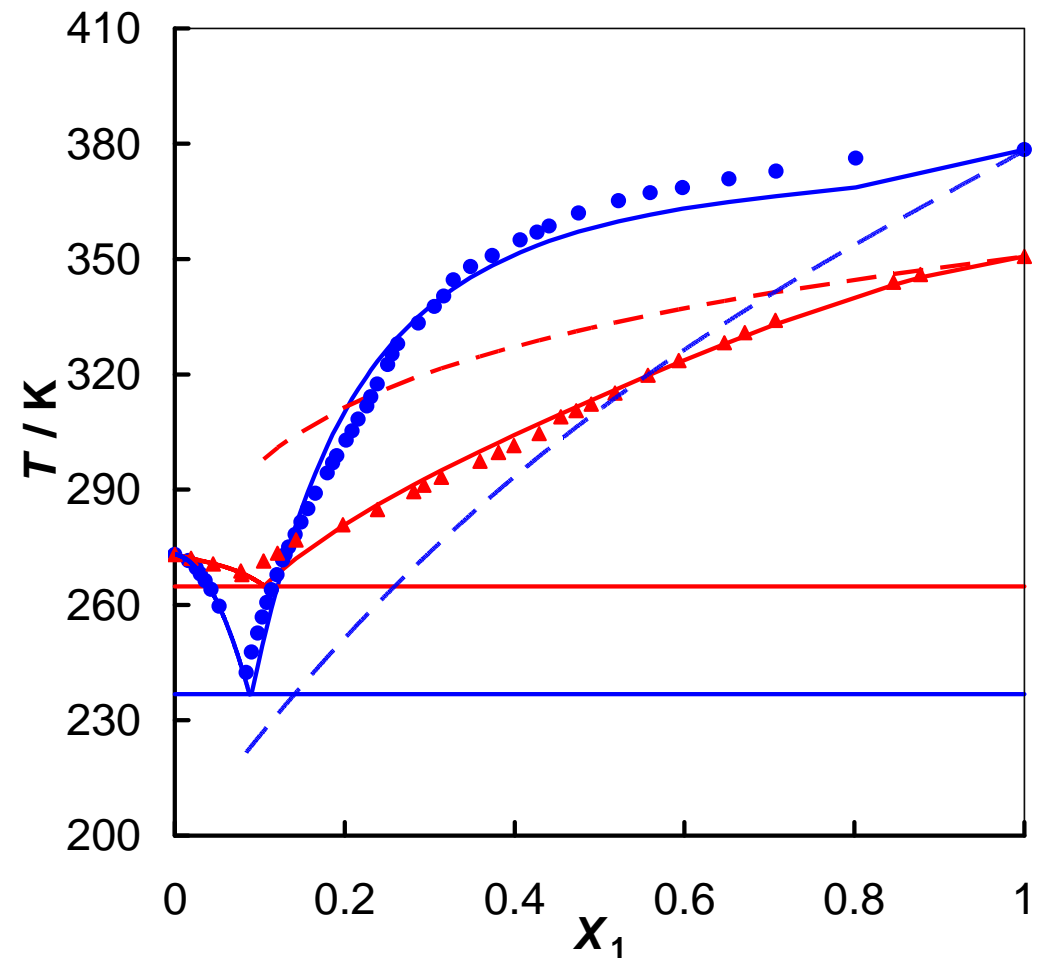

Table 3. Experimental phase equilibrium temperatures, $T^{\mathrm{SLE}}$, for $\left\{[\mathrm{EMPYR}]\left[\mathrm{CF}_{3} \mathrm{SO}_{3}\right]+\right.$ solvent $\}$ binary systems: $x_{1}$, mole fraction; $\gamma_{1}$, experimental activity coefficient of the IL.

\begin{tabular}{|c|c|c|c|c|c|}
\hline$x_{1}$ & $T^{\mathrm{SLE}} / \mathrm{K}$ & $\gamma_{1}$ & $x_{1}$ & $T^{\mathrm{SLE}} / \mathbf{K}$ & $\gamma_{1}$ \\
\hline \multicolumn{6}{|c|}{ Water } \\
\hline 0.0000 & 273.2 & 1.00 & 0.2087 & 305.3 & 2.24 \\
\hline 0.0160 & 271.5 & 1.07 & 0.2159 & 308.4 & 2.25 \\
\hline 0.0252 & 269.7 & 1.15 & 0.2258 & 311.8 & 2.25 \\
\hline 0.0299 & 268.0 & 1.23 & 0.2308 & 314.2 & 2.26 \\
\hline 0.0356 & 266.4 & 1.28 & 0.2384 & 317.5 & 2.28 \\
\hline 0.0425 & 264.0 & 1.35 & 0.2506 & 322.6 & 2.30 \\
\hline 0.0519 & 259.7 & 1.41 & 0.2555 & 325.3 & 2.33 \\
\hline 0.0838 & 242.5 & 2.01 & 0.2623 & 328.0 & 2.34 \\
\hline 0.0903 & 247.8 & 2.07 & 0.2866 & 333.4 & 2.27 \\
\hline 0.0974 & 252.7 & 2.11 & 0.3055 & 337.7 & 2.23 \\
\hline 0.1030 & 256.9 & 2.16 & 0.3166 & 340.4 & 2.21 \\
\hline 0.1083 & 260.7 & 2.20 & 0.3278 & 344.6 & 2.23 \\
\hline 0.1137 & 264.0 & 2.22 & 0.3480 & 348.1 & 2.18 \\
\hline 0.1202 & 267.9 & 2.24 & 0.3736 & 350.9 & 2.09 \\
\hline 0.1267 & 271.7 & 2.27 & 0.4064 & 355.0 & 1.99 \\
\hline 0.1300 & 273.2 & 2.26 & 0.4262 & 357.0 & 1.94 \\
\hline
\end{tabular}


Table 3. Cont.

\begin{tabular}{llllll}
\hline 0.1342 & 275.1 & 2.26 & 0.4405 & 358.6 & 1.90 \\
0.1418 & 278.4 & 2.25 & 0.4751 & 362.0 & 1.82 \\
0.1485 & 281.6 & 2.26 & 0.5224 & 365.2 & 1.71 \\
0.1565 & 285.1 & 2.26 & 0.5595 & 367.3 & 1.62 \\
0.1652 & 289.1 & 2.27 & 0.5977 & 368.6 & 1.54 \\
0.1795 & 294.4 & 2.25 & 0.6521 & 370.9 & 1.44 \\
0.1860 & 297.0 & 2.25 & 0.7078 & 372.9 & 1.35 \\
0.1905 & 298.9 & 2.25 & 0.8015 & 376.3 & 1.22 \\
0.2015 & 302.9 & 2.25 & 1.0000 & 378.5 & 1.00 \\
\hline & \multicolumn{7}{c}{1 -Butanol } & & & \\
\hline 0.7388 & 351.5 & 1.06 & 0.8713 & 366.3 & 1.03 \\
0.7620 & 353.7 & 1.05 & 0.8885 & 368.4 & 1.03 \\
0.7839 & 355.9 & 1.04 & 0.9125 & 370.6 & 1.02 \\
0.8135 & 359.0 & 1.03 & 0.9430 & 373.2 & 1.01 \\
0.8368 & 361.6 & 1.03 & 0.9624 & 375.3 & 1.01 \\
0.8529 & 363.8 & 1.03 & 1.0000 & 378.5 & 1.00 \\
\hline
\end{tabular}

Table 4. Experimental phase equilibrium temperatures, $T^{\mathrm{SLE}}$, for $\left\{[\mathrm{PMPYR}]\left[\mathrm{CF}_{3} \mathrm{SO}_{3}\right]+\right.$ solvent \} binary systems: $x_{1}$, mole fraction; $\gamma_{1}$, experimental activity coefficient of the IL.

\begin{tabular}{cccccc}
\hline $\boldsymbol{x}_{\mathbf{1}}$ & $\boldsymbol{T}^{\mathrm{SLE}} / \mathbf{K}$ & \multicolumn{1}{c}{$\boldsymbol{\gamma}_{\mathbf{1}}$} & $\boldsymbol{x}_{\mathbf{1}}$ & $\boldsymbol{T}^{\mathrm{SLE}} / \mathbf{K}$ & $\boldsymbol{\gamma}_{\mathbf{1}}$ \\
\hline 0.0000 & 273.2 & 1.00 & 0.3991 & 301.5 & 0.31 \\
0.0189 & 272.2 & 0.97 & 0.4287 & 304.6 & 0.34 \\
0.0451 & 270.7 & 0.95 & 0.4543 & 309.0 & 0.39 \\
0.0775 & 268.8 & 0.90 & 0.4724 & 310.6 & 0.41 \\
0.0788 & 267.9 & 0.87 & 0.4901 & 312.3 & 0.42 \\
0.1044 & 271.5 & 0.23 & 0.5180 & 315.2 & 0.46 \\
0.1209 & 273.5 & 0.22 & 0.5570 & 319.8 & 0.52 \\
0.1427 & 277.0 & 0.23 & 0.5934 & 323.6 & 0.58 \\
0.1978 & 280.9 & 0.21 & 0.6470 & 328.3 & 0.65 \\
0.2385 & 284.9 & 0.22 & 0.6708 & 330.9 & 0.69 \\
0.2813 & 289.5 & 0.24 & 0.7069 & 334.1 & 0.75 \\
0.2932 & 291.2 & 0.25 & 0.8461 & 344.0 & 0.92 \\
0.3138 & 293.3 & 0.26 & 0.8775 & 346.0 & 0.96 \\
0.3591 & 297.4 & 0.28 & 1.0000 & 350.7 & 1.00 \\
0.3810 & 299.7 & 0.30 & & & \\
\hline & & & $1-B u t a n o l$ & & \\
\hline 0.0698 & 295.6 & 1.32 & 0.4554 & 320.4 & 0.66 \\
0.0896 & 296.8 & 1.10 & 0.4827 & 322.0 & 0.66 \\
0.1041 & 297.7 & 0.99 & 0.5071 & 323.5 & 0.67 \\
0.1119 & 298.3 & 0.95 & 0.5417 & 325.6 & 0.69 \\
0.1309 & 299.4 & 0.86 & 0.5698 & 327.7 & 0.72 \\
0.1528 & 300.8 & 0.79 & 0.5922 & 329.1 & 0.73 \\
0.1735 & 302.1 & 0.74 & 0.6202 & 330.6 & 0.74 \\
\hline & & & &
\end{tabular}


Table 4. Cont.

\begin{tabular}{|c|c|c|c|c|c|}
\hline 0.2050 & 304.0 & 0.69 & 0.6444 & 331.9 & 0.75 \\
\hline 0.2384 & 306.2 & 0.66 & 0.6776 & 334.2 & 0.79 \\
\hline 0.2681 & 307.9 & 0.63 & 0.7160 & 336.5 & 0.81 \\
\hline 0.2897 & 309.4 & 0.63 & 0.7585 & 338.8 & 0.84 \\
\hline 0.3117 & 310.9 & 0.63 & 0.7962 & 340.6 & 0.86 \\
\hline 0.3330 & 312.2 & 0.62 & 0.8372 & 342.4 & 0.88 \\
\hline 0.3535 & 313.4 & 0.62 & 0.8850 & 344.3 & 0.89 \\
\hline 0.3716 & 314.8 & 0.63 & 0.9284 & 346.4 & 0.92 \\
\hline 0.3961 & 316.4 & 0.63 & 0.9570 & 348.1 & 0.95 \\
\hline 0.4206 & 318.0 & 0.64 & 1.0000 & 350.7 & 1.00 \\
\hline \multicolumn{6}{|c|}{ 1-Hexanol } \\
\hline 0.0863 & 310.4 & 2.21 & 0.5027 & 328.8 & 0.85 \\
\hline 0.1164 & 312.2 & 1.78 & 0.5298 & 329.9 & 0.84 \\
\hline 0.1457 & 313.8 & 1.53 & 0.5633 & 331.0 & 0.83 \\
\hline 0.1736 & 315.2 & 1.37 & 0.5965 & 332.4 & 0.83 \\
\hline 0.2026 & 316.6 & 1.25 & 0.6343 & 333.8 & 0.83 \\
\hline 0.2344 & 318.0 & 1.15 & 0.6781 & 335.5 & 0.83 \\
\hline 0.2595 & 319.1 & 1.09 & 0.7085 & 336.8 & 0.83 \\
\hline 0.2886 & 320.2 & 1.03 & 0.7544 & 338.6 & 0.84 \\
\hline 0.3196 & 321.3 & 0.97 & 0.7954 & 340.5 & 0.86 \\
\hline 0.3586 & 322.8 & 0.92 & 0.8482 & 342.7 & 0.87 \\
\hline 0.3796 & 323.7 & 0.91 & 0.8946 & 344.8 & 0.90 \\
\hline 0.4207 & 325.2 & 0.87 & 0.9474 & 347.1 & 0.92 \\
\hline 0.4519 & 326.4 & 0.85 & 1.0000 & 350.7 & 1.00 \\
\hline 0.4800 & 327.7 & 0.85 & & & \\
\hline \multicolumn{6}{|c|}{ 1-Octanol } \\
\hline 0.0253 & 318.1 & 10.67 & 0.3984 & 334.4 & 1.35 \\
\hline 0.0344 & 320.0 & 8.53 & 0.4457 & 335.2 & 1.24 \\
\hline 0.0456 & 321.7 & 6.93 & 0.5018 & 336.2 & 1.15 \\
\hline 0.0557 & 323.2 & 6.05 & 0.5409 & 337.1 & 1.10 \\
\hline 0.0676 & 324.3 & 5.23 & 0.5787 & 337.9 & 1.07 \\
\hline 0.0867 & 325.5 & 4.29 & 0.6299 & 338.8 & 1.01 \\
\hline 0.1175 & 327.2 & 3.40 & 0.6673 & 339.6 & 0.99 \\
\hline 0.1580 & 328.9 & 2.71 & 0.7047 & 340.2 & 0.96 \\
\hline 0.1666 & 329.3 & 2.62 & 0.7514 & 341.3 & 0.94 \\
\hline 0.1980 & 330.2 & 2.28 & 0.7962 & 342.4 & 0.92 \\
\hline 0.2396 & 331.1 & 1.96 & 0.8445 & 343.8 & 0.92 \\
\hline 0.2809 & 332.1 & 1.74 & 0.8986 & 345.8 & 0.93 \\
\hline 0.3151 & 332.8 & 1.60 & 0.9386 & 347.5 & 0.95 \\
\hline 0.3582 & 333.7 & 1.46 & 1.0000 & 350.7 & 1.00 \\
\hline \multicolumn{6}{|c|}{ 1-Decanol } \\
\hline 0.0155 & 331.4 & 30.66 & 0.5131 & 342.4 & 1.43 \\
\hline 0.0489 & 333.4 & 10.54 & 0.5470 & 342.4 & 1.34 \\
\hline 0.0689 & 335.0 & 7.98 & 0.5580 & 342.7 & 1.33 \\
\hline 0.0878 & 335.6 & 6.41 & 0.5915 & 342.8 & 1.26 \\
\hline 0.1015 & 336.3 & 5.70 & 0.5998 & 342.7 & 1.24 \\
\hline
\end{tabular}


Table 4. Cont.

\begin{tabular}{llllll}
\hline 0.1223 & 336.9 & 4.85 & 0.6407 & 343.1 & 1.18 \\
0.1533 & 338.0 & 4.04 & 0.6798 & 343.1 & 1.11 \\
0.1928 & 338.9 & 3.32 & 0.7310 & 343.5 & 1.05 \\
0.2324 & 339.6 & 2.83 & 0.7648 & 343.8 & 1.01 \\
0.2729 & 340.2 & 2.47 & 0.8094 & 344.5 & 0.98 \\
0.3126 & 340.8 & 2.21 & 0.8554 & 345.3 & 0.96 \\
0.3532 & 341.1 & 1.98 & 0.8848 & 346.2 & 0.96 \\
0.3929 & 341.4 & 1.80 & 0.9445 & 347.8 & 0.95 \\
0.4337 & 341.7 & 1.65 & 0.9822 & 350.2 & 1.00 \\
0.4738 & 341.9 & 1.52 & 1.0000 & 350.7 & 1.00 \\
\hline
\end{tabular}

On the basis of the phase diagram presented in Figure 3 for the $\left\{[\mathrm{PMPYR}]\left[\mathrm{CF}_{3} \mathrm{SO}_{3}\right]+\right.$ an alcohol $\}$, the following trends can be seen: for all the mixtures, simple eutectic systems were observed with complete miscibility in liquid phase; and the solubility of the IL in alcohols decreases as the length of the carbon chain of an alcohol increases; for alcohols the eutectic temperatures were below $290 \mathrm{~K}$, the lowest temperature we could attain in these systems.

Figure 3. (Solid + liquid) phase equilibria of $\left\{[\mathrm{PMPYR}]\left[\mathrm{CF}_{3} \mathrm{SO}_{3}\right]+\right.$ an alcohol $\}$ :

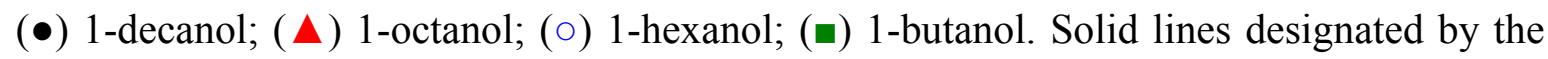
Wilson equation. Dotted line represents an ideal solubility.

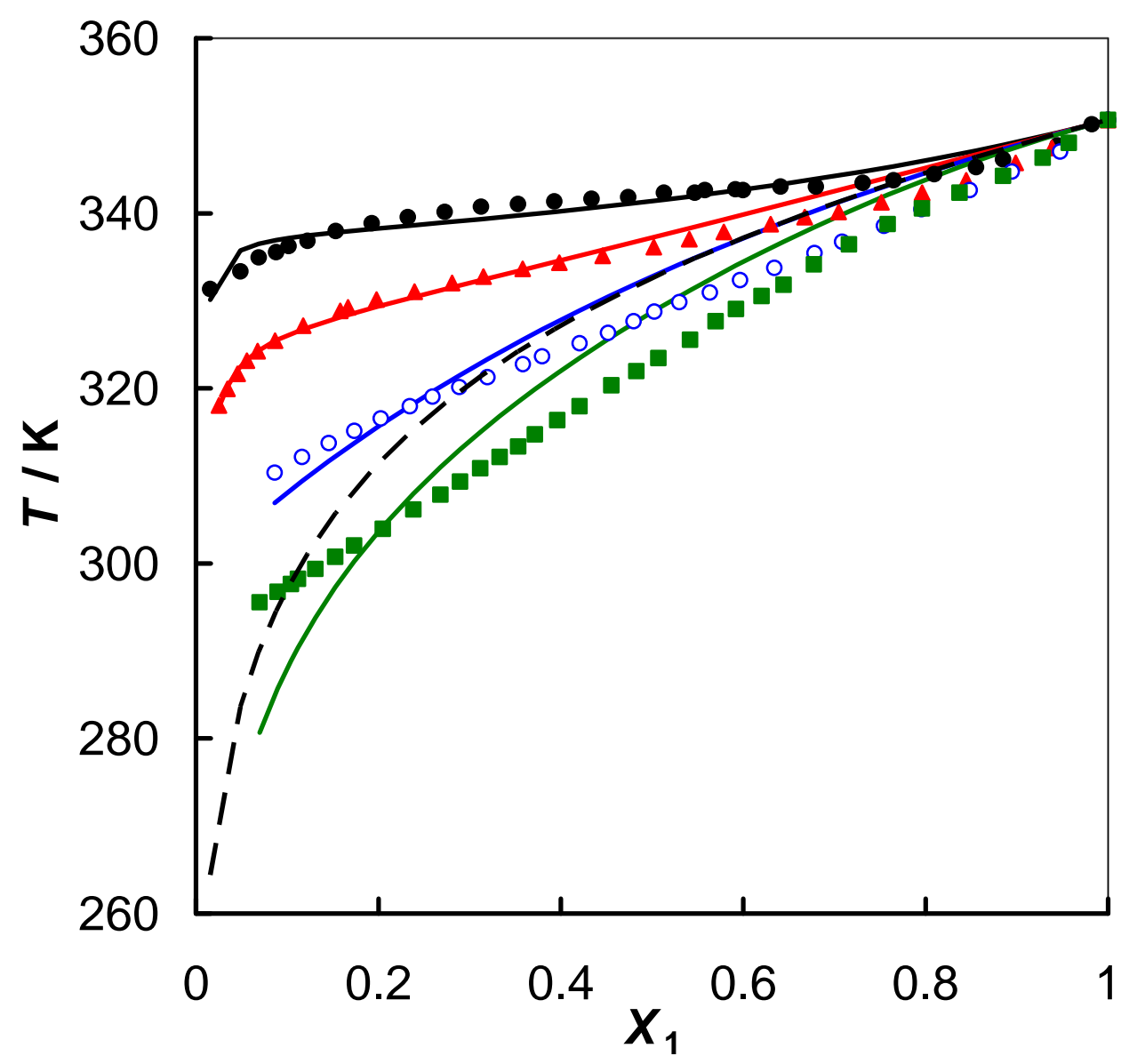


The comparison of SLE data for two investigated ILs (IL +1 -butanol) with the same anion $\left[\mathrm{CF}_{3} \mathrm{SO}_{3}\right]^{-}$but different cations $\left([\mathrm{EMPYR}]^{+}\right.$and $\left.[\mathrm{PMPYR}]^{+}\right)$shows the differences connected only with the melting temperature of the IL. The liquidus curve of [EMPYR] $\left[\mathrm{CF}_{3} \mathrm{SO}_{3}\right]$ in 1-butanol is at much higher temperature. It means that this IL is miscible with 1-butanol over the liquidus curve at a higher temperature. Thus the increasing of the alkane chain length at the pyrrolidinium ring decreases the melting temperature of the IL and increases the solubility in water and in alcohols. This is probably the influence of the more asymmetric cation of the $[\mathrm{PMPYR}]\left[\mathrm{CF}_{3} \mathrm{SO}_{3}\right]$ and its influence on the interaction with a polar solvent. Furthermore, it was observed that the solubility of [EMPYR] $\left[\mathrm{CF}_{3} \mathrm{SO}_{3}\right]$ in water was lower than the ideal solubility (see activity coefficients $\gamma_{1}>1$ in Table 3) but those of [PMPYR] $\left[\mathrm{CF}_{3} \mathrm{SO}_{3}\right]$ in water and in the shorter chain length alcohols was higher than the ideal solubility (see activity coefficients $\gamma_{1}<1$ in Table 4). The solubility of [EMPYR] $\left[\mathrm{CF}_{3} \mathrm{SO}_{3}\right]$ is lower in water than in 1-butanol, and those of [PMPYR] $\left[\mathrm{CF}_{3} \mathrm{SO}_{3}\right]$ is higher in water than in 1-butanol. This is the evidence, that the more asymmetric cation of the [PMPYR] $\left[\mathrm{CF}_{3} \mathrm{SO}_{3}\right]$ increases the solubility in alcohol in comparison with water. It has to be the van der Waals interaction between the alkane chains of cation and that of an alcohol.

A simple eutectic system with complete miscibility in the liquid phase for binary systems $\{\mathrm{IL}+$ water $\}$ was observed earlier for many ionic liquids, i.e., for imidazolium-based ILs, 1-butyl-3-methylimidazolium thiocyanate [BMIM][SCN] [26], 1-butyl-3-methylimidazolium tosylate [BMIM][TOS] [32], 1-ethyl-3-methylimidazolim ethylsulfate [EMIM][EtSO $]$ [33,34], and for ammonium-based ionic liquids, i.e., for didecyldimethylammonium nitrate [DDA] $\left[\mathrm{NO}_{3}\right]$ [35], or for ethyl-(2-hydroxyethyl)-dimethyl-ammonium tetrafluoroborate $\mathrm{C}_{2} \mathrm{BF}_{4}$ [36]. Water, being a polar solvent, can interact with the polar anion as $\left[\mathrm{EtSO}_{4}\right]^{-}$or $\left[\mathrm{NO}_{3}\right]^{-}$, but on the other side the long alkane chains as $\left(\mathrm{C}_{10}\right)$ of $[\mathrm{DDA}]^{+}$cation are hydrophobic, hence there is little interaction of water with cation, thus mainly the anion entity is favoured in the $\{\mathrm{IL}+$ water $\}$ mixtures.

Mixtures of $\{\mathrm{IL}+$ an alcohol $\}$ have been discussed in many papers and can reveal the complete miscibility in the liquid phase (liquid at room temperature ILs) [33]; the simple eutectic mixtures with complete miscibility in the liquid phase as the ILs measured in this work and for example [BMIM][TOS] [32], or $[\mathrm{DDA}]\left[\mathrm{NO}_{3}\right]$ [35]. They may reveal the SLE phase diagrams with the immiscibility gap in the liquid phase [36]. However, the most popular is the LLE phase diagram with the upper critical solution temperature (UCST) [37-42]. An interesting analysis of LLE in the mixtures of imidazolium-based ILs with an alcohol and water has shown the most important factors that govern the phase behaviour of ionic liquids with these solvents [37,38]. A systematic decrease in solubility was observed with an increase of the alkyl chain length of an alcohol [37-42].

\section{Modelling}

Since the solid-solid phase transitions were observed in our ILs, and the change of heat capacity at the melting temperature was assumed to be $\Delta_{\text {fus }} C \mathrm{p}=\Delta_{\text {fus }} H / T_{\text {fus, }}$, a general thermodynamic equation relating temperature, $T^{\mathrm{SLE}}$ and the mole fraction of the IL, $x_{1}$ in the water and in the 1-alcohols have been fitted to all the sets of experimental SLE data [43]:

$$
-\ln x_{1}=\frac{\Delta_{\text {fus }} H}{R}\left(\frac{1}{T}-\frac{1}{T_{\text {fus }}}\right)+\frac{\Delta_{\text {tr }} H}{R}\left(\frac{1}{T}-\frac{1}{T_{\text {tr }}}\right)-\frac{\Delta_{\text {fus }} C_{p}}{R}\left(\ln \frac{T}{T_{\text {fus }}}+\frac{T_{\text {fus }}}{T}-1\right)+\ln \gamma_{1}
$$


where $x_{1}, \gamma_{1}, \Delta_{\text {fus }} H, \Delta_{\text {fus }} C \mathrm{p}, T_{\text {fus }}, T, \Delta_{\text {tr }} H$ and $T_{\text {tr }}$ are mole fraction, activity coefficient, enthalpy of fusion, difference in solute heat capacity between the liquid and solid phase at melting temperature, melting temperature, equilibrium temperature, enthalpy of the solid-solid phase transition and transition temperature, respectively. If a solid-solid phase transition occurs before fusion, the solubility equation for temperatures below that of the phase transition must include the effect of the transition. In this work the (solid-solid) phase transition was far below the experimental points. The enthalpy of melting is assumed to be temperature independent, whereas the activity coefficient is temperature as well as solubility dependent.

In this work three equations were used to describe the experimental data: the Wilson [44], UNIQUAC [45] and the NRTL equation proposed by Renon and Prausnitz [46]. For the ILs used in this work, the molar volumes for the hypothetical subcooled liquids were calculated by the group contribution method described by Barton [30]. The equations used have two adjustable parameters $P_{1}$ and $P_{2}$ (and the parameter $\alpha$ which is fixed, additionally for the NRTL eqn.), which are determined by minimization of the objective function $\mathrm{F}\left(P_{1}, P_{2}\right)$, defined as follows:

$$
\mathrm{F}\left(P_{1}, P_{2}\right)=\sum_{i=1}^{n}\left[T_{\exp , i}-T_{\text {calc }, i}\left(x_{i}, P_{1}, P_{2}\right)\right]^{2}
$$

where $n$ denotes the number of experimental points. The Marquardt algorithm for solving non-linear least squares problems was successfully used in this work. As a measure of the reliability of the correlations, the root-mean-square deviation of temperature, $\sigma_{\mathrm{T}}$, has been calculated according to the following definition:

$$
\sigma_{\mathrm{T}}=\left\{\sum_{i=1}^{n} \frac{\left(T_{\mathrm{exp}, i}-T_{\mathrm{calc}, i}\right)^{2}}{n-2}\right\}^{1 / 2}
$$

The values of the parameters and the corresponding root-mean-square deviations of temperature, $\sigma_{\mathrm{T}}$, are reported in Table 5 and the resulting curves are presented together with the experimental points in Figures 2 and 3 for $\{\mathrm{IL}+$ water $\}$ and $\left\{[\mathrm{PMPYR}]\left[\mathrm{CF}_{3} \mathrm{SO}_{3}\right]+\right.$ an alcohol $\}$ binary systems, respectively.

The results obtained indicate that the equations used were appropriate for providing a reliable description of the SLE measured in this work. The average value of the root-mean-square deviations of temperature, $\sigma_{\mathrm{T}}$, for the best NRTL equation was $1.78 \mathrm{~K}$. In this work, the value of parameter $\alpha$, a constant of proportionality similar to the nonrandomness constant of the NRTL equation, had different values in the calculations for different binary systems ( $\alpha=0.1, \alpha=0.2, \alpha=0.3, \alpha=0.4, \alpha=0.5)$ to obtain the best correlation.

All the mixtures investigated in this work, show positive or negative deviations from ideality. The differences from ideality were not significantly higher, or lower than one and the values of activity coefficients of ILs in the saturated solutions ranged from 0.62 to 30 . It is generally known that for small solubility (i.e., [PMPYR][CF $\left.3 \mathrm{SO}_{3}\right]$ in 1-decanol), the activity coefficients are higher than one. 
Table 5. Correlation of the (solid + liquid) phase equilibrium data of the $\{\mathrm{IL}+$ water, or + an alcohol\} mixtures by means of Wilson, UNIQUAC and NRTL equations: values of parameters and measures of deviations.

\begin{tabular}{|c|c|c|c|c|c|c|}
\hline & \multicolumn{3}{|c|}{ Parameters } & \multicolumn{3}{|c|}{ RMSD } \\
\hline & Wilson & UNIQUAC & NRTL & Wilson & UNIQUAC & NRTL \\
\hline \multirow{3}{*}{ Solvent } & $\lambda_{12}-\lambda_{22}$ & $u_{12}-u_{22}$ & $g_{12}-g_{22}$ & \multirow{3}{*}{\multicolumn{2}{|c|}{$\sigma_{\mathrm{T}} /(\mathrm{K})$}} & \\
\hline & $\lambda_{21}-\lambda_{11}$ & $u_{21}-u_{11}$ & $g_{21}-g_{11}$ & & & \\
\hline & $\mathrm{J} \cdot \mathrm{mol}^{-1}$ & $\mathrm{~J} \cdot \mathrm{mol}^{-1}$ & $\mathrm{~J} \cdot \mathrm{mol}^{-1}$ & & & \\
\hline \multicolumn{7}{|c|}{$[\mathrm{EMPYR}]\left[\mathrm{CF}_{3} \mathrm{SO}_{3}\right]$} \\
\hline \multirow{2}{*}{ Water } & -6000.99 & - & 11108.24 & \multirow{2}{*}{5.68} & \multirow{2}{*}{ - } & \multirow{2}{*}{$1.77^{\mathrm{a}}$} \\
\hline & 14643.09 & - & -2407.88 & & & \\
\hline \multirow{2}{*}{ 1-Butanol } & 86142.98 & 6189.93 & 9151.76 & \multirow{2}{*}{2.52} & \multirow{2}{*}{0.82} & \multirow{2}{*}{$0.77^{\mathrm{b}}$} \\
\hline & 2260.38 & -3213.90 & -4863.26 & & & \\
\hline \multicolumn{7}{|c|}{$[\mathrm{PMPYR}]\left[\mathrm{CF}_{3} \mathrm{SO}_{3}\right]$} \\
\hline \multirow{2}{*}{ Water } & -11445.59 & - & 1729.43 & \multirow{2}{*}{2.53} & \multirow{2}{*}{-} & \multirow{2}{*}{$2.04^{\mathrm{c}}$} \\
\hline & 7593.47 & - & -5366.87 & & & \\
\hline \multirow{2}{*}{ 1-Butanol } & -4777.45 & -2236.81 & -6688.84 & \multirow{2}{*}{5.62} & \multirow{2}{*}{5.01} & \multirow{2}{*}{$2.45^{\mathrm{a}}$} \\
\hline & 3836.80 & 9586.35 & 16576.57 & & & \\
\hline \multirow{2}{*}{ 1-Hexanol } & 59160.06 & -1875.88 & -10141.14 & \multirow{2}{*}{3.50} & \multirow{2}{*}{3.01} & \multirow{2}{*}{$1.97^{\mathrm{d}}$} \\
\hline & -186.86 & 4414.00 & 19911.02 & & & \\
\hline \multirow{2}{*}{ 1-Octanol } & 7114.00 & -1005.80 & -398.14 & \multirow{2}{*}{1.40} & \multirow{2}{*}{1.41} & \multirow{2}{*}{$1.41^{\mathrm{c}}$} \\
\hline & 1263.48 & 2427.37 & 7364.46 & & & \\
\hline \multirow{2}{*}{ 1-Decanol } & 9729.67 & -797.71 & 2740.31 & \multirow{2}{*}{1.20} & \multirow{2}{*}{3.01} & \multirow{2}{*}{$2.09^{\mathrm{e}}$} \\
\hline & 2622.93 & 2348.27 & 8010.29 & & & \\
\hline
\end{tabular}

\section{Experimental Section}

\subsection{Materials}

The IL investigated here, 1-ethyl-1-methylpyrrolidinium triflate, [EMPYR][CF $\left.3 \mathrm{SO}_{3}\right]$ and 1-propyl1-methylpyrrolidinium triflate [PMPYR] $\left[\mathrm{CF}_{3} \mathrm{SO}_{3}\right]$, with a purity of $>99$ mass fraction, were purchased from Liquids Technologies (iolitec GmbH\& Co. KG, Denzlingen, Germany). Water for the solubility measurements was twice distilled, degassed, deionized and filtered with Milipore Elix 3. The alcohols used in phase equilibria measurements were purchased from Sigma Aldrich Chemie GmbH (Steinheim, Germany). All the alcohols were fractionally distilled in order to achieve a mass percent purity (checked by using gas chromatography) of $>99.8 \%$ and then stored over freshly activated molecular sieve (type $4 \AA$ from Union Carbide). The water content of ILs and the solvents was determined by the Karl-Fisher titration (method TitroLine KF). Samples of the IL and the solvents were dissolved in dry methanol and titrated in $2.5 \mu \mathrm{L}$ steps. The analysis showed that the water mass fraction in the pure IL, in solvents and in the mixtures with the ionic liquid, was $<270 \times 10^{-6}$. 


\subsection{Differential Scanning Microcalorimetry}

The temperature of fusion and (solid-solid) phase transition, enthalpy of fusion and (solid-solid) phase transition have been measured using a differential scanning microcalorimetry technique (DSC). The applied scan rate was $5 \mathrm{~K} \cdot \mathrm{min}^{-1}$, with a power and recorder sensitivities of $16 \mathrm{~mJ} \cdot \mathrm{s}^{-1}$ and $5 \mathrm{mV}$, respectively. The apparatus (Thermal Analysis Q200, USA with Liquid Nitrogen Cooling System) was calibrated with a 0.999999 mol fraction purity indium sample. The average value of the melting temperature was $\left(T_{\text {fus }} \pm 0.1\right) \mathrm{K}$ (average over three scans). The repeatability of that value was $\pm 0.1 \mathrm{~K}$. The enthalpy of fusion was $\left(\Delta_{\text {fus }} H \pm 0.1\right) \mathrm{kJ} \cdot \mathrm{mol}^{-1}$ and that of (solid-solid) phase transition was $\left(\Delta_{\mathrm{tr}} H \pm 0.1\right) \mathrm{kJ} \cdot \mathrm{mol}^{-1}$. The new data are listed in Table 2.

\subsection{Apparatus and Experimental Procedure}

(Solid + liquid) phase equilibria measurements were carried out using a visual method, according to procedures described previously [47]. Mixtures of the IL + solvent were prepared by weighing the pure components within an accuracy of $1 \times 10^{-4} \mathrm{~g}$. The sample was heated very slowly (at less than 2 $\mathrm{K} \mathrm{h}^{-1}$ ) with continuous stirring inside a Pyrex glass cell placed in thermostated water bath. The temperature of the disappearance of the solid phase (detected visually) was measured with a calibrated Gallenkamp Autotherm II thermometer totally immersed in the water bath. The uncertainty of temperature and compositions (mole fractions) measurements was $\pm 0.1 \mathrm{~K}$ and \pm 0.0005 , respectively. The reproducibility of the measured saturated phase boundary temperatures was better than $0.1 \mathrm{~K}$.

The solubility of the (IL + solvent) mixtures was studied in most of the systems over the whole range of concentration. In the case of alcohols only the ionic liquid rich mole fraction liquidus curves were measured. The eutectic points in the systems with alcohols were not detected because of the very low temperature.

\section{Conclusions}

(Solid + liquid) phase equilibria have been measured in binary systems containing 1-alkyl-1-methylpyrrolidinium triflate ionic liquid and water, or an alcohol. The results obtained indicate that the structure of the pyrrolidinium cation (including the cation's symmetry and size, i.e., the alkyl substituents and their length) can influence the melting temperature and the phase behaviour of these ionic liquids. The ionic liquid with the more asymmetric cation $h\left([\mathrm{PMPYR}]\left[\mathrm{CF}_{3} \mathrm{SO}_{3}\right]\right)$ as the lower melting temperature and higher solubility in water and in alcohols. In the case of alcohols the influence is small and seems to be more significant at higher temperatures. Pyrrolidinium-based ILs are highly ordered hydrogen-bonded substances that may interact strongly with water and an alcohol revealing complete miscibility in the liquid phase. The specific interaction of the IL with an alcohol (association between the oxygen of the anion and the hydroxyl group of an alcohol) increases solubility in low molecular weight alcohols as shown in Figure 3. The pyrrolidinium-based ILs are novel compounds which should find new applications in the selective separation of liquids. The results of the correlation with the two parameters NRTL equation displayed acceptable standard deviation. 


\section{Acknowledgements}

Funding for this research was provided by the Warsaw University of Technology. Author wish gratefully acknowledge Sci. M. Królikowski and A. Kropiewnicka for the technical assistance.

\section{References and Notes}

1. Lewandowski, A.; Świderska, A. New composite solid electrolytes based on a polymer and ionic liquids. Solid State Ionics 2004, 169, 21-24.

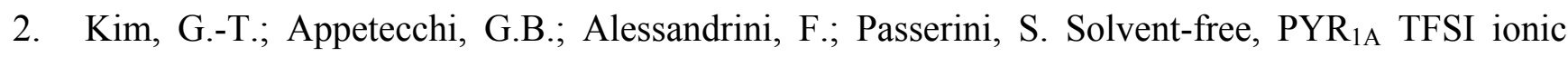
liquid-based ternary polymer electrolyte systems I. Electrochemical characterization. J. Power Dources 2007, 171, 861-869.

3. Lu, J.; Yan, F.; Texter, J. Advanced applications of ionic liquids in polymer science. Prog. Polym. Sci. 2009, 34, 431-448.

4. Pont, A.-L.; Marcilla, R.; De Meatza, I.; Grande, H.; Mecerreyes, D. Pyrrolidinium-based polymeric ionic liquids as mechanically and electrochemically stable polymer electrolytes. J. Power Sources 2009, 188, 558-563.

5. Bando, Y.; Katayama, Y.; Miura, T. Electrodeposition of palladium in a hydrophobic 1-n-butyl-1-methylpyrrolidinium bis(trifluoromethylsulfonyl)imide room-temperature ionic liquid. Electrochim. Acta 2007, 53, 87-91.

6. Azaceta, E.; Tena-Zaera, R.; Marcilla, R.; Fantini, S.; Echeberria, J.; Pomposo, J.A. Electrochemical deposition of $\mathrm{ZnO}$ in a room temperature ionic liquid: 1-Butyl-1-methylpyrrolidinium bis(trifluoromethanesulfonyl)imide. Electrochem. Commun. 2009, 11, 2184-2186.

7. Borisenko, N.; Ispas, A.; Zschippang, E.; Liu, Q.; Zein El Abedin, S.; Bund, A.; Endres, F. In situ STM and EQCM studies of tantalum electrodeposition from $\mathrm{TaF}_{5}$ in the air- and water-stable ionic liquid 1-butyl-1methylpyrrolidinium bis(trifluoromethylsulfonyl)amide. Electrochim. Acta 2009, 54, 1519-1528.

8. Fujimori, T.; Fujii, K.; Kanzaki, R.; Chiba, K.; Yamamoto, H.; Umebayashi, Y. Ishiguro, S. Conformational structure of room temperature ionic liquid $N$-butyl- $N$-methyl-pyrrolidinium bis(trifluoromethanesulfonyl)imide-Raman spectroscopic study and DFT calculations. J. Mol. Liq. 2007, 131-132, 216-224.

9. Anouti, M.; Jones, J.; Boisset, A.; Jacquemin, J.; Caillon-Caravanier, M.; Lemordant, D. Aggregation behavior in water of new imidazolium and pyrrolidinium alkycarboxylates protic ionic liquids. J. Coll. Interf. Sci. 2009, 340, 104-111.

10. Lombardo, M.; Easwar, S.; Pasi, F.; Trombini, C.; Dhavale, D.D. Protonated arginine and lysine as catalysts for the direct asymmetric aldol reaction inionic liquids. Tetrahedron 2008, 64, 9203-9207.

11. Poole C.F. Chromatographic and spectroscopic methods for the determination of solvent properties of room temperature ionic liquids. J. Chromatogr. 2004, 1037, 49-82.

12. Valderrama, J.O.; Rojas, R.R. Critical properties of ionic liquids. Revisited. Ind. Eng. Chem. Res. 2009, 48, 6890-6900.

13. Earle, M.J.; Esperanca, J.M.S.S.; Gilea, M.A.; Canongia Lopes, J.N.; Rebelo, L.P.N. The distillation and volatility of ionic liquids. Nature 2006, 439, 831-834. 
14. Kato, R.; Gmehling, J. Systems with ionic liquids: Measurements of VLE and $\gamma^{\infty}$ data and prediction of their thermodynamic behavior using original UNIFAC, mod. UNIFAC(Do) and COSMO-RS(01). J. Chem. Thermodyn. 2005, 37, 603-619.

15. Nebig, S.; Liebert, V.; Gmehling, J. Measurements and prediction of activity coefficients at infinite dilution $\left(\gamma^{\infty}\right)$, vapor-liquid equilibria (VLE) and excess enthalpies $\left(H^{\mathrm{E}}\right)$ of binary systems with 1,1-dialkyl-pyrrolidinium bis(trifluoromethylsulfonyl)imide using mod. UNIFAC (Dortmund). Fluid Phase Equilib. 2009, 277, 61-67.

16. Waliszewski, D.; Stępniak, I.; Piekarski, H.; Lewandowski, A. Heat capacities of ionic liquids and their heats of solution in molecular liquids. Thermochim. Acta 2005, 433, 149-152.

17. Gardas, R.L.; Coutinho, J.A.P. Extension of the Ye and Shreeve group contribution method for density estimation of ionic liquids in a wide range of temperatures and pressures. Fluid Phase Equilib. 2008, 263, 26-32.

18. Brennecke, J.F.; Maginn, E.J. Ionic liquids: Innovative fluids for chemical processing. AIChE J. 2001, 47, 2384-2389.

19. Holbrey, J.D.; López-Martin, I.; Rothenberg, G.; Seddon, K.R.; Sivero, G.; Zheng, X. Desulfurisation of oils using ionic liquids: Selection of cationic and anionic components to enhance extraction efficiency. Green Chem. 2008, 10, 87-92.

20. Pereiro, A.B.; Rodríguez, A. An ionic liquid proposed as solvent in aromatic hydrocarbon separation by liquid extraction. AIChE J. 2010, 56, 381-386.

21. Westerholt, A.; Liebert, V.; Gmehling, J. Influence of ionic liquids on the separation factor of three standard separation problems. Fluid Phase Equilib. 2009, 280, 56-60.

22. Domańska, U.; Redhi, G.G.; Marciniak, A. Activity coefficients at infinite dilution measurements for organic solutes and water in the ionic liquid 1-butyl-1-methylpyrrolidinium trifluoromethanesulfonate using GLC. Fluid Phase Equilib. 2009, 278, 97-102.

23. Freire, M.G.; Neves, C.M.S.S.; Carvalho, P.J.; Gardas, R.L.; Fernandes, A.M.; Marrucho, I.M.; Santos, L.M.N.B.F.; Coutinho, J.A.P. Mutual solubilities of water and hydrophobic ionic liquids. J. Phys. Chem. B 2007, 111, 1382-1389.

24. Freire, M.G.; Ventura, S.P.M.; Santos, L.M.N.B.F.; Marrucho, I.M.; Coutinho, J.A.P. Evaluation of COSMO-RS for the prediction of LLE and VLE of water and ionic liquids binary systems. Fluid Phase Equilib. 2008, 268, 74-84.

25. Marciniak, A.; Karczemna, E. Influence of cation structure on binary liquid-liquid equilibria for systems containing ionic liquids based on trifluoromethanesulfonate anion with hydrocarbons. J. Phys. Chem. B 2010, DOI:10.1021/jp100994d.

26. Domańska, U.; Laskowska, M.; Pobudkowska, A. Phase equilibria study of the binary sytems (1-butyl-3-methylimidazolium thiocyanate ionic liquid + organic solvent, or water). J. Phys. Chem. B 2009, 113, 6397-6404.

27. Domańska, U.; Laskowska, M.; Marciniak, A. Phase equilibria of (1-ethyl-3-methylimidazolium ethylsufate + hydrocarbon, ketone, ether) binary systems. J. Chem. Eng. Data 2008, 53, 498-502.

28. Domańska, U.; Królikowski, M.; Ślesińska, K. Phase equilibria study of the binary system (ionic liquid + thiophene): desulfurization process. J. Chem. Thermodyn. 2009, 41, 1303-1311. 
29. Blesic M.; Canongia Lopes, J.N.; Pádua, A.A.H.; Shimizu, K.; Costa Gomes, M.F.; Rebelo, L.P.N. Phase equilibria in ionic liquid-aromatic compound mixtures, including benzene fluorination effects. J. Phys. Chem. B 2009, 113, 7631-7636.

30. Barton, A.F.M. CRC Handbook of Solubility Parameters; CRC Press: Boca Raton, FL, USA, 1985; p. 64.

31. Strechan, A.A.; Paulechka, Y.U.; Kabo, A.G.; Blkhiin, A.V.; Kabo, G.J. 1-Butyl-3methylimidazolium tosylate ionic liquid: Heat capacity, thermal stability, and phase equilibrium of its binary mixtures with water and caprolactam. J. Chem. Eng. Data 2007, 52, 1791-1799.

32. Domańska, U.; Królikowski, M. Phase equilibria study of the binary systems (1-butyl-3-methylimidazolium tosylate ionic liquid + water, or organic solvent). J. Chem. Thermodyn. 2010, 42, 355-362.

33. Domańska, U.; Laskowska, M. Phase equilibria and volumetric properties of (1-ethyl-3-methylimidazolium ethylsulfate + alcohol or water) binary systems. J. Solution Chem. 2008, 37, 1271-1287.

34. Domańska, U.; Laskowska, M. Phase equilibria and volumetric properties of (1-ethyl-3-methylimidazolium ethylsulfate + alcohol or water) binary systems. J. Solution Chem. 2008, 37, 1271-1287.

35. Domańska, U.; Ługowska, K.; Pernak, J. Phase equilibria of didecyldimethylammonium nitrate ionic liquid with water and organic solvents. J. Chem. Thermodyn. 2007, 39, 729-736.

36. Domańska, U. Thermophysical properties and thermodynamic phase behavior of ionic liquids. Thermochim. Acta. 2006, 448, 19-30.

37. Crosthwaite, J.M.; Aki, S.N.V.K.; Maginn, E.J.; Brennecke, J.F. Liquid phase behavior of imidazolium-based ionic liquids with alcohols. J. Phys. Chem. B 2004, 108, 5113-5119.

38. Crosthwaite, J.M.; Aki, S.N.V.K.; Maginn, E.J.; Brennecke, J.F. Liquid phase behavior of imidazolium-based ionic liquids with alcohols: Effect of hydrogen bonding and non-polar interactions. Fluid Phase Equilib. 2005, 228-229, 303-309.

39. Wu, C.-T.; Marsh, K.N.; Deev, A.V.; Boxall, J.A. Liquid-liquid equilibria of room-temperature ionic liquids and butan-1-ol. J. Chem. Eng. Data 2003, 48, 486-493.

40. Sahandzhieva, K.; Tuma, D.; Breyer, S.; Kamps, A.P.-S.; Maurer, G. Liquid-liquid equilibrium in mixtures of the ionic liquid 1-n-butyl-3-methylimidazolium hexafluorophosphate and an alcohol. J. Chem. Eng. Data 2006, 51, 1516-155.

41. Heintz, A.; Klasen, D.; Lehmann, J.K.; Wertz, Ch. Excess molar volumes and liquid-liquid equilibria of the ionic liquid 1-methyl-3-octyl-imidazolium tetrafluoroborate mixed with butan-1-ol and pentan-1-ol. J. Solution Chem. 2005, 34, 1135-1144.

42. Domańska, U.; Rękawek, A.; Marciniak, A. Solubility of 1-alkyl-3-ethylimidazolium-based ionic liquids in water and 1-octanol. J. Chem. Eng. Data. 2008, 53, 1126-1132.

43. Prausnitz, J.M.; Lichtenthaler, R.N.; Azevedo, E.G. Molecular Thermodynamics of Fluid-Phase Equilibria, 2nd ed.; Prentice-hall Inc.: Englewood Cliffs, NJ, USA, 1986.

44. Wilson, G.M. Vapor-liquid equilibrium. XI. A new expression for the excess free energy of mixing. J. Am. Chem. Soc. 1964, 86, 127-130.

45. Abrams, D.S.; Prausnitz, J.M. Statistical thermodynamics of liquid mixtures: a new expression for the excess Gibbs energy of partly or completely miscible systems. AIChE J. 1975, 21, 116-128. 
46. Renon, H.; Prausnitz, J.M. Local composition in thermodynamic excess functions for liquid mixtures. AIChE J. 1968, 14, 135-144.

47. Domańska, U. Vapour-liquid-solid equilibrium of eicosanoic acid in one and two component solvents. Fluid Phase Equilib. 1986, 26, 201-220.

(C) 2010 by the authors; licensee MDPI, Basel, Switzerland. This article is an open-access article distributed under the terms and conditions of the Creative Commons Attribution license (http://creativecommons.org/licenses/by/3.0/). 